$\begin{array}{ccc} & \\ & \text { International Journal of Case Reports } \\ \text { (ISSN:2572-8776) }\end{array}$

\title{
Laparoscopic approach for pancreato-splenic abscess from disseminated melioidosis: Surgical outcome and review of literature
}

\author{
Hiang Jin Tan, Adrian Kah Heng Chiow, Nita Thiruchelvam, Siong San Tan, Lip Seng Lee \\ Hepatopancreatobiliary Unit, Department of Surgery, Changi General Hospital, Singapore 529889.
}

\begin{abstract}
Melioidosis is a severe systemic infection caused by Burkholderia pseudomallei. It commonly affects the lungs, liver and kidneys. Pancreatic and splenic abscess from melioidosis is rare, with few reports in the literature. We present a series of 4 patients with disseminated melioidosis of pancreas and spleen who required surgical intervention. A MEDLINE database review was conducted. Relevant publications were evaluated and demographic data, clinical, radiological findings as well as management options were collected. We found 10 case reports describing this clinical condition. In our series, median age was 57 . Median operative time 260 minutes. All four patients failed trial of antibiotic therapy

and required surgery. Three underwent distal pancreatosplenectomy and one underwent splenectomy alone. Laparoscopic distal pancreatosplenectomy was successful in two patients. Median length of stay 11.5 days. No post-operative complications and mortality reported. Surgery is indicated in failed medical therapy and laparoscopic approach is safe and feasible.
\end{abstract} ${ }^{*}$ Correspondence to Author: Dr. Lee Lip Seng Hepatopancreatobiliary Unit, Department of Surgery, Changi General Hospital, 2 Simei Street 3, Singapore 529889.

How to cite this article:

Hiang Jin Tan, Adrian Kah Heng Chiow, Nita Thiruchelvam, Siong San Tan, Lip Seng Lee.Laparoscopic approach for pancreato-splenic abscess from disseminated melioidosis: Surgical outcome and review of literature. International Journal of Case Reports,2021 $5: 241$

Keywords: laparoscopic surgery, melioidosis, spleen, pancreas

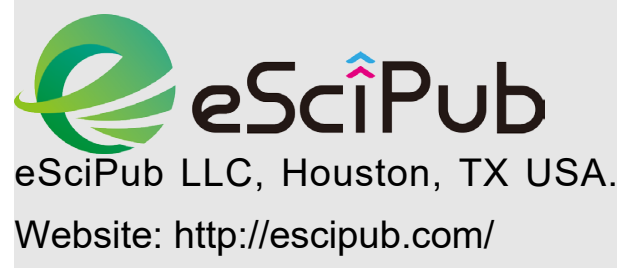




\section{INTRODUCTION}

Melioidosis is a severe systemic infectious disease caused by Burkholderia pseudomallei, a Gram-negative bacillus with bipolar staining. Melioidosis is commonly found in soil, groundwater, ponds and rice paddies throughout endemic regions, which are Southeast Asia and Northern Australia. ${ }^{[1]}$ The disease is transmitted through contact with contaminated soil of water by percutaneous inoculation, aerosol inhalation or ingestion of contaminated food or water. With a fatality rate of $19-36 \%$ in endemic areas, this disease should not be taken lightly and appropriate treatment should be instituted early. $[2,3]$ Melioidosis is well reported for its propensity to cause abscesses, with liver and splenic abscess being the more common form. [4] However, there is only a sparsity of case reports in the literature. We present a case series of pancreato-splenic abscess from melioidosis requiring surgical intervention and a review of its literature.

\section{Methods}

All the cases that were admitted to our institution requiring surgical intervention for pancreatosplenic melioidosis from January 2016 to December 2019 were reviewed. We also conducted a MEDLINE database review of the relevant medical literature published in English from year 1980 to 2021 and identified all reported cases of pancreatic/splenic abscesses caused by melioidosis that required surgical intervention using the following keywords: melioidosis, pancreas, spleen, and abscess. Relevant publications were evaluated and demographic data as well as findings and clinical outcomes were collected.

\section{Results}

A total of 10 articles were found describing this clinical condition. All patients failed conservative management and required surgical interventions. In this series, we present 4 cases of pancreato-splenic abscesses from melioidosis requiring surgery. The patients' characteristic and clinical information as well as outcome are summarized in Table 1. Median age of patients in our series was 57 , with all patients being male. Three patients had predisposing medical condition of diabetes mellitus. All patients failed initial conservative treatment with antibiotics and underwent distal pancreatectomy and splenectomy. No postoperative complications and mortality was reported. Follow up scans revealed resolution of intra-abdominal abscesses.

\section{CASE SERIES}

\section{Case 1}

Case 1 was a 58-year-old man with no past medical history, admitted to us for fever with chills and rigors for 1-week duration. On admission, he was lucid with normal clinical examinations of heart, lungs and abdomen. However, he developed type 1 respiratory failure secondary to acute pulmonary oedema shortly after admission. He was intubated and transferred to intensive care unit [ICU] for inotropic support. Blood investigations revealed haemoglobin levels of $13.0 \mathrm{~g} / \mathrm{dl}$, white cell count of $22.6 \times 10^{3} / \mathrm{uL}$, platelet levels of $218 \times 10^{3} / \mathrm{uL}$. His inflammatory markers were raised with $C$ reactive protein [CRP] levels of $250.8 \mathrm{mg} / \mathrm{L}$ and procalcitonin levels of $10 \mathrm{ug} / \mathrm{L}$.

Liver function test performed revealed bilirubin of $30.5 \mathrm{umol} / \mathrm{L}$, alkaline phosphatase [ALP] of $261 \mathrm{U} / \mathrm{L}$, alkaline transaminase [ALT] of $56 \mathrm{U} / \mathrm{L}$ and aspartate transaminase [AST] of $50 \mathrm{U} / \mathrm{L}$. His renal function was deranged with sodium levels of $121 \mathrm{mmol} / \mathrm{L}$, potassium of $4.3 \mathrm{mmol} / \mathrm{L}$, creatinine of $90 \mathrm{umol} / \mathrm{L}$ and urea of $5.3 \mathrm{mmol} / \mathrm{L}$. Blood cultures grew Burkholderia pseudomallei, and candida.

Computed tomography [CT] scan of the abdomen and pelvis was performed to identify source of infection. It revealed multiple irregular hypodense areas within the spleen, subcapsular abscess at inferior pole of the spleen and an abscess locule abutting the pancreatic tail. [Figure 1a] He was started on intravenous [IV] meropenem and anidulafungin. Splenectomy was offered to the patient but he was not keen to 
Hiang Jin Tan et al,, IJCR, 2021,5:241

undergo the surgery. A repeat ultrasound of the and he was extubated on day 4 of ICU abdomen was performed 4 days later, which admission, he was initiated on renal revealed worsening of the splenic abscesses. replacement therapy [CRRT] for acute kidney Although his respiratory requirements improved injury.

Table 1: Demographics and management of pancreato-splenic abscess from melioidosis.M: male, F: female, DM: diabetes mellitus, CT: computed tomography, Lap: laparoscopic, OSA: obstructive sleep apnoea, CKD: chronic kidney disease

\begin{tabular}{|c|c|c|c|c|c|c|c|c|c|}
\hline No & $\begin{array}{l}\text { Author/Year/ } \\
\text { Reference }\end{array}$ & Gender & Age & Symptoms & Comorbidities & $\begin{array}{l}\text { White cell } \\
\text { counts [x } \\
10^{3} \\
\text { cells/uL] }\end{array}$ & $\begin{array}{l}\text { CRP } \\
{[\mathrm{mg} / \mathrm{dL}]}\end{array}$ & $\begin{array}{l}\text { Radiological } \\
\text { features }\end{array}$ & Treatment \\
\hline 1. & $\begin{array}{l}\text { Hai Chen et al., } \\
2018^{[16]}\end{array}$ & $\mathrm{M}$ & 55 & $\begin{array}{l}\text { Abdominal } \\
\text { pain, fever, loss } \\
\text { of weight }\end{array}$ & Nil & 17 & 56.6 & $\begin{array}{l}\text { Hepatic disease, } \\
\text { spleen abscess } \\
\text { and calcification }\end{array}$ & Splenectomy \\
\hline 2. & $\begin{array}{l}\text { Deng-Wei Chou } \\
\text { et al., 2016 }\end{array}$ & $F$ & 50 & $\begin{array}{l}\text { Abdominal } \\
\text { pain, fever }\end{array}$ & DM & 10.5 & 31.6 & $\begin{array}{l}\text { Splenomegaly } \\
\text { and multifocal } \\
\text { splenic } \\
\text { infarctions }\end{array}$ & Splenectomy \\
\hline 3. & $\begin{array}{l}\text { Fibi Ninan et al., } \\
2018^{[18]}\end{array}$ & $\mathrm{M}$ & 53 & $\begin{array}{l}\text { Fever, left } \\
\text { upper } \\
\text { abdominal pain }\end{array}$ & DM & nil & $9.8 \mathrm{mg} / \mathrm{L}$ & $\begin{array}{l}\text { Splenic lesions } \\
\text { with peripheral } \\
\text { calcifications }\end{array}$ & Splenectomy \\
\hline 4. & $\begin{array}{l}\text { Liv Hesstvedt et } \\
\text { al., } 2011^{[19]}\end{array}$ & $\mathrm{M}$ & 38 & $\begin{array}{l}\text { Fever, } \\
\text { abdominal pain }\end{array}$ & DM & 10.7 & $\begin{array}{l}100 \\
\mathrm{mg} / \mathrm{dl}\end{array}$ & Splenic abscess & Splenectomy \\
\hline 5. & $\begin{array}{l}\text { Miraclin AT et } \\
\text { al., 2017 [20] }\end{array}$ & $\mathrm{F}$ & Young & $\begin{array}{l}\text { Left } \text { sided } \\
\text { abdominal pain, } \\
\text { fever }\end{array}$ & $\begin{array}{l}\text { Thalassemia } \\
\text { intermedia }\end{array}$ & Nil & Nil & $\begin{array}{l}\text { Splenic abscess } \\
\text { with perisplenic } \\
\text { collection. }\end{array}$ & Splenectomy \\
\hline 6. & $\begin{array}{l}\text { Ashish } \\
\text { Jitendranath et } \\
\text { al., 2016 }\end{array}$ & $\mathrm{M}$ & 41 & $\begin{array}{l}\text { Fever, left } \\
\text { upper } \\
\text { abdominal pain }\end{array}$ & DM & 29.5 & Nil & $\begin{array}{lr}\text { Multiple } & \text { well } \\
\text { defined } & \text { splenic } \\
\text { abscess } & \\
\end{array}$ & Splenectomy \\
\hline 7. & $\begin{array}{lr}\text { Tak } & \text { Kuan } \\
\text { Chow et } & \text { al., } \\
2016^{[22]} & \end{array}$ & $M$ & 54 & $\begin{array}{l}\text { Asymptomatic - } \\
\text { Incidental } \\
\text { findings from } \\
\text { histology } \\
\text { following } \\
\text { splenectomy for } \\
\text { road traffic } \\
\text { accident }\end{array}$ & Nil & Nil & Nil & $\begin{array}{l}\text { US: free fluid in } \\
\text { left splenorenal } \\
\text { recess }\end{array}$ & Splenectomy \\
\hline 8. & $\begin{array}{l}\text { Seymour Levine } \\
\text { et al., } 1968^{[23]}\end{array}$ & $\mathrm{M}$ & 26 & $\begin{array}{l}\text { Fever, loss of } \\
\text { weight }\end{array}$ & DM & 8.2 & Nil & $\begin{array}{l}\text { Fluoroscopy: } \\
\text { splenomegaly }\end{array}$ & Splenectomy \\
\hline 9. & $\begin{array}{l}\text { J Maytapa et al., } \\
2018^{[24]}\end{array}$ & $\mathrm{M}$ & 52 & $\begin{array}{l}\text { Fever, } \\
\text { abdominal pain }\end{array}$ & $\mathrm{DM}$ & 12 & Nil & $\begin{array}{l}\text { CT: Multiple rim- } \\
\text { enhancing } \\
\text { hypodense } \\
\text { lesions in the } \\
\text { spleen with } \\
\text { eroding to gastric } \\
\text { fundus }\end{array}$ & $\begin{array}{l}\text { Splenectomy } \\
\text { and repair of } \\
\text { gastrosplenic } \\
\text { fistula }\end{array}$ \\
\hline 10. & $\begin{array}{l}\text { Wu YC et al., } \\
2010^{[25]}\end{array}$ & $\mathrm{M}$ & 54 & $\begin{array}{l}\text { Fever, } \\
\text { abdominal pain, } \\
\text { loss of appetite }\end{array}$ & DM & 8.2 & Nil & $\begin{array}{ll}\text { CT: } & \text { Splenic } \\
\text { abscess } & \end{array}$ & Splenectomy \\
\hline 11. & Case 1 & $\mathrm{M}$ & 58 & Fever & Nil & 22.6 & 250.8 & $\begin{array}{l}\text { CT: multiple } \\
\text { irregular } \\
\text { hypodense areas } \\
\text { within the spleen }\end{array}$ & $\begin{array}{l}\text { Lap distal } \\
\text { pancreatecto } \\
\text { my and } \\
\text { splenectomy }\end{array}$ \\
\hline 12. & Case 2 & $\bar{M}$ & 75 & Fever and URTI & DM,CKD & 9.9 & 97.6 & $\begin{array}{l}\text { CT: multiple } \\
\text { splenic } \\
\text { abscesses with } \\
\text { capsular breach } \\
\text { at the inferior } \\
\text { aspect and absular } \\
\text { subcapsul } \\
\text { collections }\end{array}$ & $\begin{array}{l}\text { lap distal } \\
\text { pancreatecto } \\
\text { my and } \\
\text { splenectomy }\end{array}$ \\
\hline 13. & Case 3 & $\mathrm{M}$ & 57 & Prolonged fever & DM,OSA & 12.8 & 85.1 & $\begin{array}{l}\text { CT: } \\
\text { splenenomegaly } \\
\text { with multiple } \\
\text { abscesses }\end{array}$ & $\begin{array}{l}\text { Lap converted } \\
\text { to open distal } \\
\text { pancreatecto } \\
\text { my with } \\
\text { splenectomy }\end{array}$ \\
\hline 14. & Case 4 & $\mathrm{M}$ & 57 & $\begin{array}{l}\text { Fever and } \\
\text { abdominal pain }\end{array}$ & DM & 10.8 & 239 & $\begin{array}{l}\text { CT: large splenic } \\
\text { abscess as well } \\
\text { as liver abscess }\end{array}$ & $\begin{array}{l}\text { Lap converted } \\
\text { to open } \\
\text { splenectomy }\end{array}$ \\
\hline
\end{tabular}


After 14 days of IV antibiotics, a repeat CT scan of the abdomen and pelvis revealed progression of the abscess in both the spleen and tail of the pancreas. [Figure 1b]. Patient finally consented for surgery. He underwent laparoscopic distal pancreatectomy and splenectomy. Intraoperatively there were multiple pus loculations at the pancreatic tail and the spleen. Postoperatively, he recovered well and completed 6 weeks of antibiotics. Post splenectomy vaccinations were also administered. His hospital stay was prolonged in view of his initial stormy presentation as well as physical deconditioning requiring inpatient rehabilitation post-operatively. He was discharged well on post-operative day [POD] 42 . He was finally discharged well and stable on post-operative day [POD] 42. A repeat CT scan of the abdomen and pelvis 7 months later showed resolution of the abscesses with the residual pancreas appeared unremarkable.

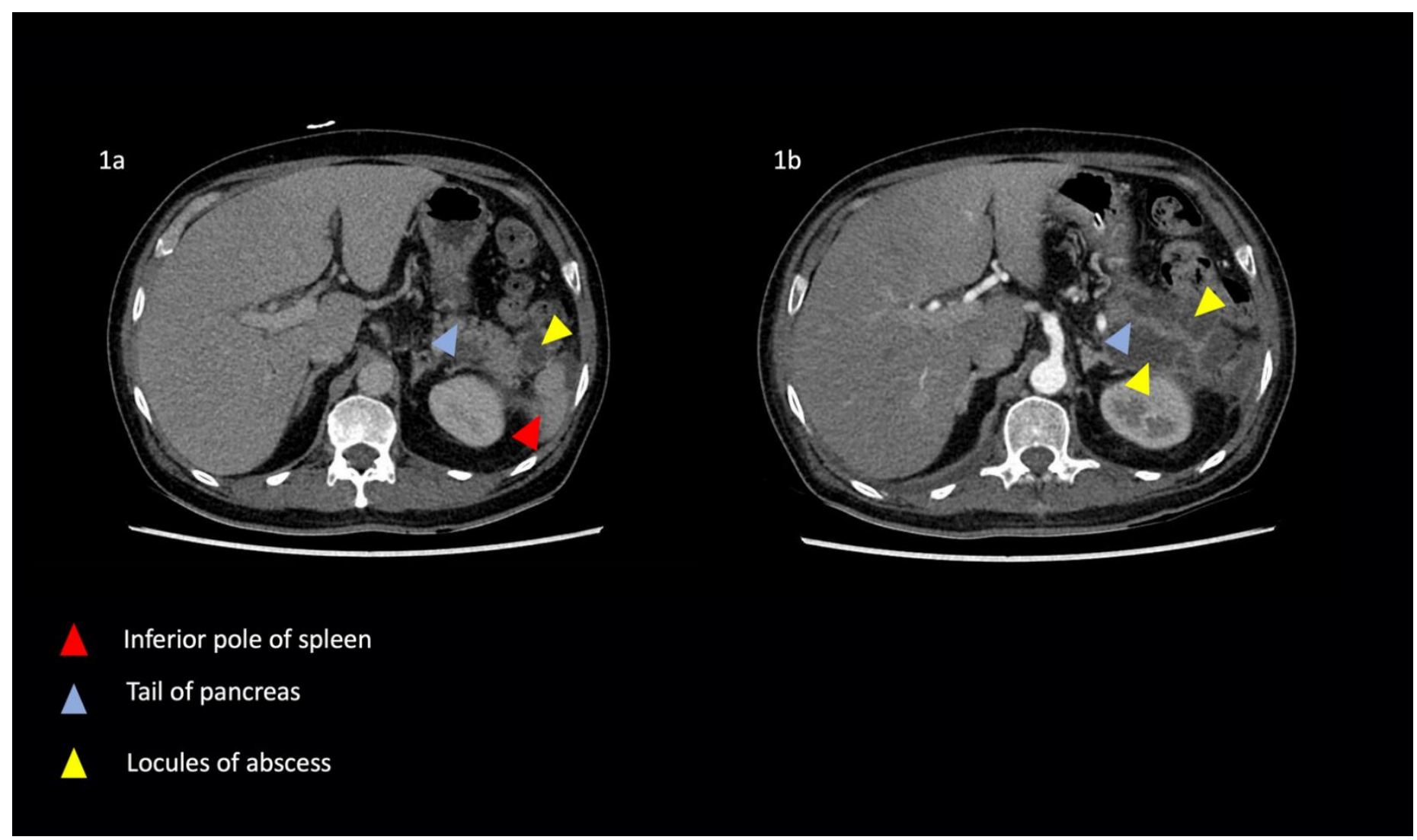

Figure 1a: CT abdomen pelvis revealed subcapsular inferior pole splenic abscess with another locule of abscess abutting the tail of the pancreas at the initial presentation to the hospital.

Figure 1b: A repeat CT after 14 days of antibiotics showed progression of infection with more coalescing abscesses in the pancreatic tail and spleen.

\section{Case 2}

Case 2 is 75-year-old man with diabetes mellitus, hypertension, hyperlipidaemia and chronic kidney disease. He was admitted to our institution for fever of 3 days' duration which was associated with symptoms of upper respiratory tract infection. Physical examination was unremarkable. Blood investigations revealed haemoglobin levels of $9.7 \mathrm{~g} / \mathrm{dl}$, white cell count of $9.9 \times 10^{3} / \mathrm{uL}$ and platelet of $218 \times 10^{3} \mathrm{uL}$. His CRP was raised at $97.6 \mathrm{mg} / \mathrm{L}$ but procalcitonin was normal at $0.37 \mathrm{ug} / \mathrm{L}$. Liver function test and renal panel were unremarkable. Blood culture grew Burkholderia pseudomallei.

CT scan of the chest, abdomen and pelvis revealed left lung upper lobe cavitation and 
multiple splenic abscesses with capsular breach at the inferior aspect and subcapsular collections. [Figure 2a] Bronchoscopy was performed in view of CT scan findings of the left lung upper lobe cavitation and melioidosis PCR was positive from bronchoscopy lavage. He was treated conservatively with intravenous antibiotics for 6 weeks and discharged with an outpatient antibiotic therapy regime. His follow up CT scan after 1 month showed reduction of left lung upper lobe cavitation but increase in size of the splenic abscesses as well as the perisplenic collection involving the tail of pancreas.
[Figure 2b] In view of the scan findings, he was offered laparoscopic distal pancreatectomy and splenectomy. Intra-operatively, there were multi-loculated large splenic abscess involving also the splenic flexure splenic hilum and tail of pancreas. Post-operatively he recovered well and discharged on POD 7 with 6 weeks of PO antibiotics. The follow up CT scan showed resolution of the abdominal abscess. He had completed 3 months of oral antibiotics for lung abscess and he is currently still on oral augmentin for chronic suppression of lung abscess.

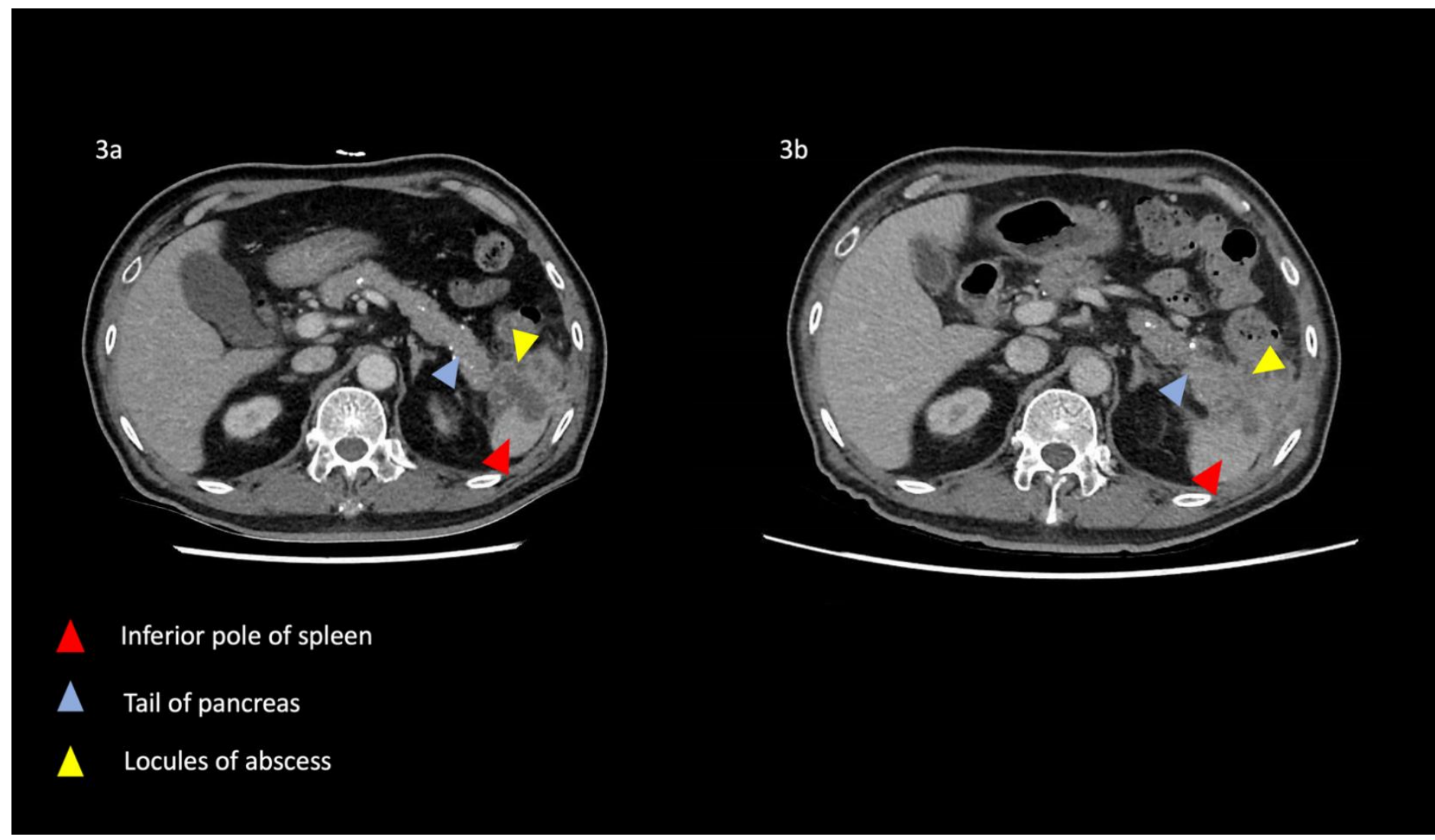

Figure 2a: Multiple locules of splenic abscess with capsular breach at the inferior aspect and subcapsular collections; there was no involvement of the pancreatic tail.

Figure $2 \mathrm{~b}$ : Increase in size of multiple splenic abscesses with abscess and progression to involve tail of pancreas.

\section{$\underline{\text { Case } 3}$}

Case 3 was a morbidly obese 57 -year-old male with diabetes mellitus, obstructive sleep apnoea and pulmonary melioidosis that was treated with 6 weeks of antibiotics 2 years ago. He was admitted to our institution after he had persistent fever for 2 weeks. On examination, there was no abdominal sign on admission.

His haemoglobin level was $15.1 \mathrm{~g} / \mathrm{dL}$, white cell count was raised at $12.8 \times 10^{3} / \mathrm{uL}$ and platelets level was $412 \times 10^{3} / \mathrm{uL}$. Renal panel and liver function test were unremarkable. His CRP level 
was raised at $85.1 \mathrm{mg} / \mathrm{L}$ and procalcitonin was $0.29 \mathrm{ug} / \mathrm{L}$. Blood culture grew Burkholderia pseudomallei.

CT scan of the abdomen and pelvis revealed an enlarged spleen with multiple abscesses in the spleen with one locule of abscess abutting the tail of pancreas. [Figure 3a] Melioidosis serology was positive. He was started on IV Ceftazidime for 6 weeks' duration and discharged well and stable. However, during his follow up at 3 months, he was noted to have a right neck lump and was admitted for further work up. CT neck revealed a $3.9 \mathrm{~cm}$ multi-septated, rim enhancing hypodense abscess collection in the right upper neck with another smaller $1.2 \mathrm{~cm}$ abscess right level II cervical lymph node. Needle aspiration of the abscess yielded frank pus and melioidosis PCR was positive too.

$A$ repeated $\mathrm{CT}$ thorax, abdomen and pelvis were then performed in view of the recurrent disseminated melioidosis. It showed interval increase in splenic abscess and a new abscess in the pancreatic tail. [Figure 3b] $\mathrm{He}$ was counselled for splenectomy in view of failed conservative management with IV antibiotics. $\mathrm{He}$ underwent laparoscopic distal pancreatectomy with splenectomy. However, it was converted to open in view of bulky and swollen spleen from the abscess and scarring of the splenic hilum from medial spreading of the splenic abscess that prevented safe dissection.

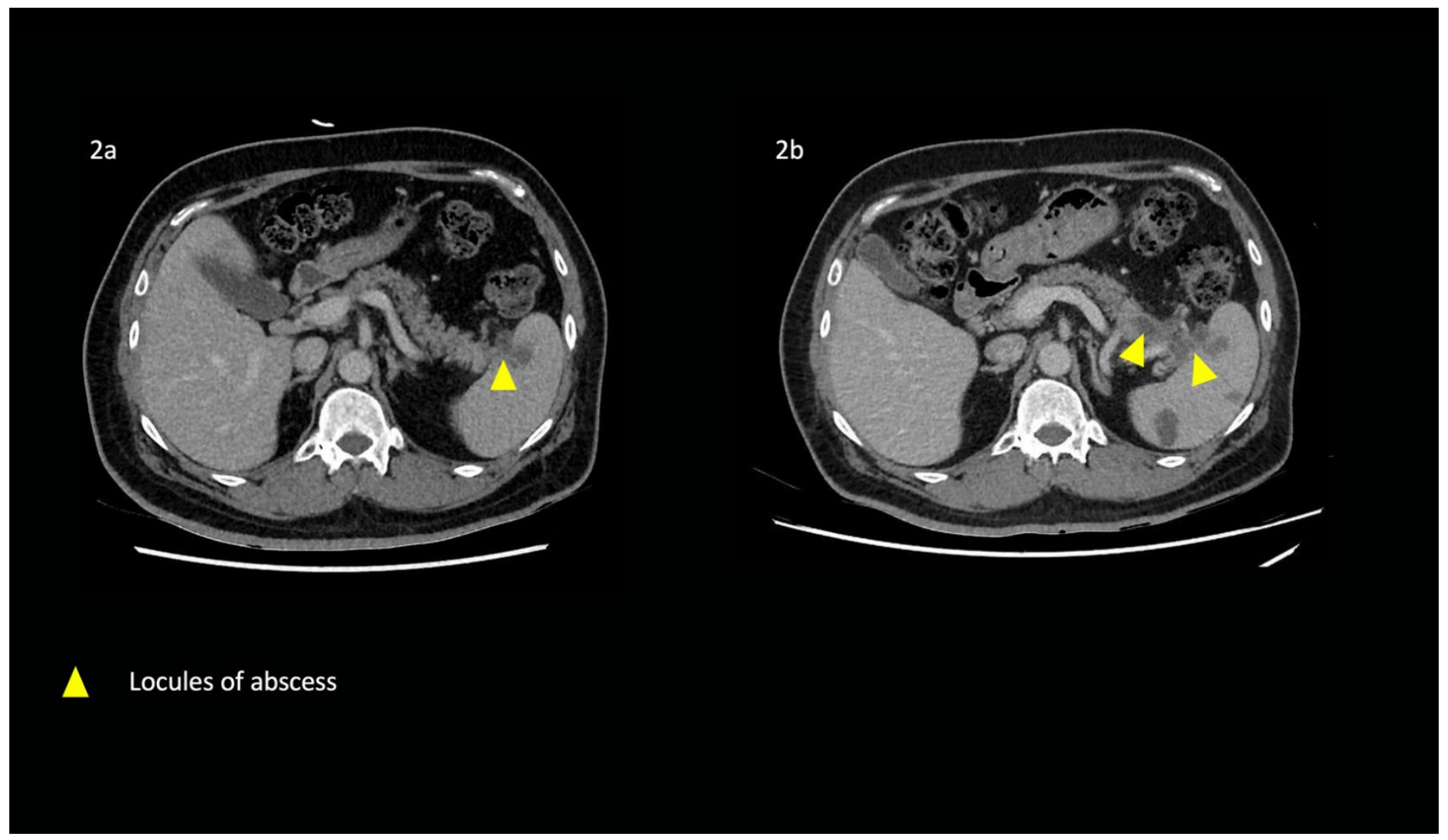

Figure 3a: Splenic abscess abutting the tail of pancreas at initial presentation to hospital.

Figure 3b: interval increase in splenic abscess and new abscess in the pancreatic tail.

Post operatively, he recovered well and completed 6 weeks of IV antibiotics via outpatient antibiotic therapy. He was discharged well and stable on POD 14. He was seen at outpatient clinic 1-month post discharge where he was well with no new symptoms. He completed oral antibiotics and was discharged from our follow up.

\section{Case 4}

Case 4 was a 57-year-old male with diabetes mellitus who presented with one week of fever. 
On physical examination, there was epigastric tenderness. His white cell count was mildly elevated at $10.8 \times 10^{3} / \mathrm{UI}$. His haemoglobin and platelet counts were normal. Inflammatory markers of CRP and procalcitonin were raised at $239 \mathrm{mg} / \mathrm{L}$ and $40.5 \mathrm{ug} / \mathrm{L}$ respectively. His liver function test was also deranged with ALP of 245 U/L ALT $65 \mathrm{U} / \mathrm{L}$ and AST $72 \mathrm{U} / \mathrm{L}$. Blood culture grew Burkholderia pseudomallei.

CT scan of the abdomen and pelvis revealed a large splenic abscess. [Figure 4a] $\mathrm{He}$ was initially treated conservatively with IV Ceftazidime. The interval CT abdomen pelvis after 2 weeks of IV antibiotic treatment showed worsening of the splenic abscess. [Figure 4b] He was counselled and consented for laparoscopic splenectomy. The surgery was converted to open due to dense adhesion from the inflammatory tissue of the ruptured splenic abscess. There was no post-operative complication and he was discharged well and stable on POD 9. He was seen in our outpatient specialist clinic where he was well and asymptomatic. A repeat CT at 12 months showed resolution of the abscesses. He completed 6 weeks of IV ceftazidime and PO Bactrim for 6 months.

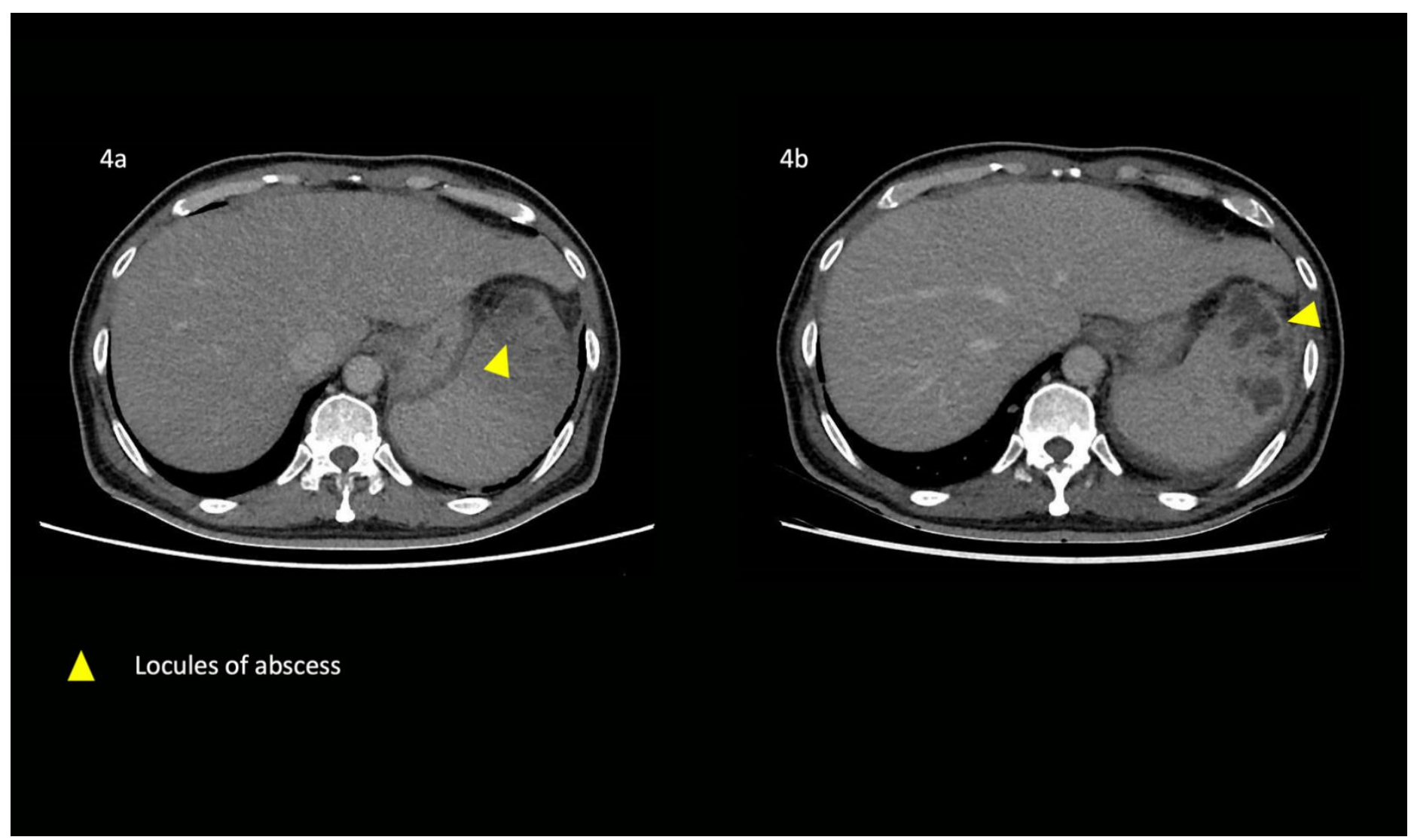

Figure 4a: Large multiloculated splenic abscess at initial presentation

Figure 4b: CT scan after 2 weeks of IV antibiotic therapy demonstrating progression of splenic abscess

\section{Surgical technique for laparoscopic distal pancreatectomy and splenectomy}

The patient was positioned in a 15-degree reverse Trendelenburg with slight tilting up of the left side of the body. A $12 \mathrm{~mm}$ port for camera was inserted to supraumbilical area using open cut-down technique. Further $12 \mathrm{~mm}$ port and 2 other $5 \mathrm{~mm}$ ports were inserted as indicated in Figure 5. The Lesser sac was entered by taking down the gastrocolic ligament, the splenic flexure was then mobilised. Combination of blunt dissection with laparoscopic sucker and 
sharp dissection with Harmonic scalpel were applied. The splenic artery was dissected out from superior pancreas, it was then doubly ligated with Hem-o-lok [West Closure Systems, Research Triangle Park, NC] and transected. The lateral to medial approach was used by mobilising the spleen fully towards the tail of pancreas. The tail of pancreas was then transected together with the splenic vein with powered Echelon flex $60 \mathrm{~mm}$ blue reload. The pancreatic stump was then over-run with prolene $4 / 0$ to ensure adequate hemostasis. Evicel Fibrin Sealant was applied to the pancreatic stump. Two surgical drains were placed to the left subphrenic space and to the pancreatic stump respectively. A small wound extension was performed at umbilical port site for specimen retrieval.

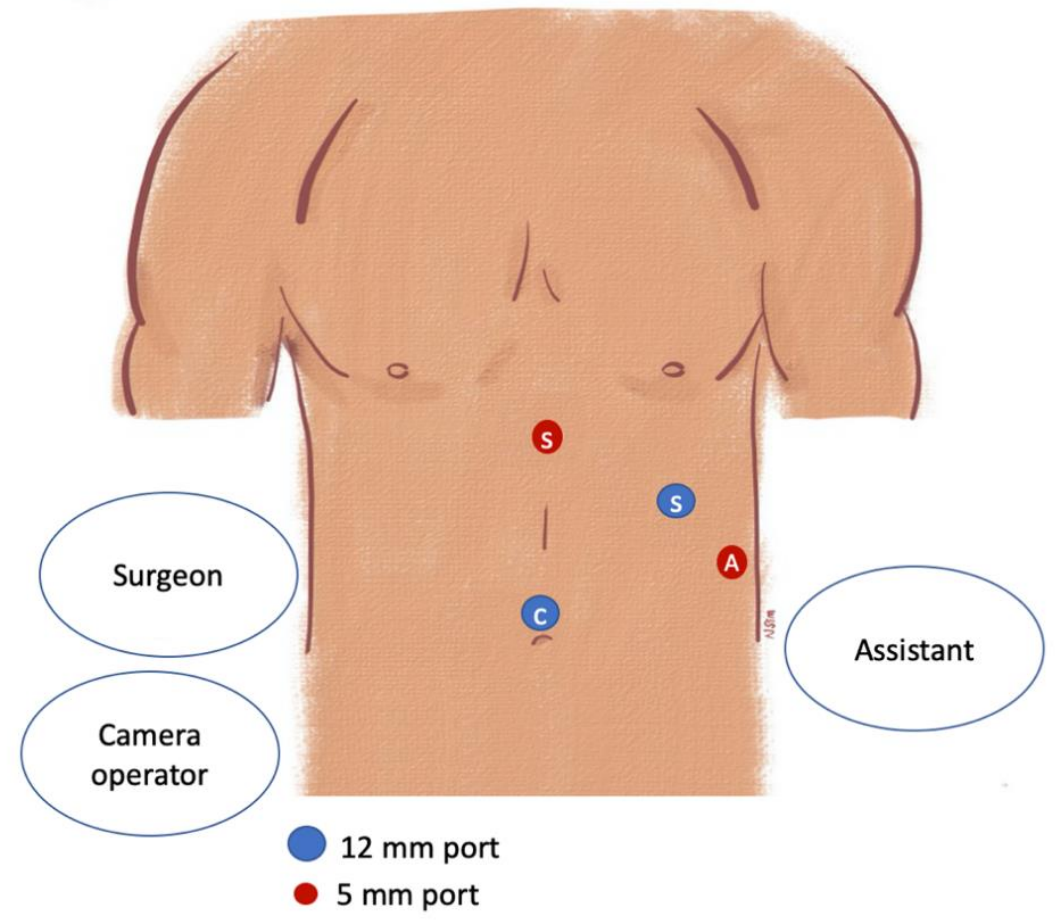

Figure 5: Port placements during laparoscopic distal pancreatectomy and splenectomy.

S: surgeon, A: assistant, C: camera port

\section{DISCUSSION}

Melioidosis is an emerging infectious disease caused by the non-spore forming, gram negative soil saprophytic bacillus Burkholderia pseudomallei. It mainly occurs in pandemic areas such as Southeast Asia and northern Australia region. ${ }^{[5]}$ The disease is acquired from contact with contaminated soil or water through abrasions and minor cuts, as well as by the inhalation of aerosols and ingestion.

Clinical manifestation in human can be in various forms, from acute fulminant septicaemia to localized soft tissue lesions, visceral abscesses [more commonly in the spleen, liver and lung], chronic melioidosis and latent melioidosis. Latent melioidosis is defined as an asymptomatic infection, which can later develop into active disease at an indeterminate time after the initial infection. ${ }^{[6]}$ The incidence of septic shock occurred in $40 \%$ of cases and the mortality rate ranging from $26 \%$ to $80 \%$. ${ }^{[7]}$ In our series, case 1 developed acute fulminant septicaemia with respiratory failure requiring ventilator support while the rest of the cases developed localized abscesses as well as chronic melioidosis. Most patients who contracted the disease have well-known predisposing factors, such as diabetes mellitus, 
chronic kidney disease, chronic lung disease or immunocompromised. [8]

In our review, majority patients are male, $12[85.7 \%$ ]. Median age was 57 , ranging from 38 to 74 years old. Most common risk factor is diabetes mellitus, with 10 patients predisposed to it [71.4\%]. All patient failed conservative treatment with antibiotics and required surgical intervention. All the patients who underwent distal pancreatectomy and splenectomy did not have grade $B / C$ pancreatic leak. None of our patients who underwent surgery had Clavien Dindo 3 and above complications.

The most common involved sites of melioidosis are lung, blood stream, liver and spleen. [9] Clinical presentations are based on the site infected, with fever always being the predominant symptom. In our series, all 4 patients developed fever prior to admission.

Common sonographic findings of visceral melioidosis consist of small [less than $2 \mathrm{~cm}$ ], discrete, multi-loculated lesions with a target-like appearance due to early central necrosis of the affected tissue and prominent fibrin content. CT is the most accurate modality with the hallmark being a low attenuation area with enhancing rim. [10] In our series. CT scan of the abdomen and pelvis revealed multiple abscesses in the spleen and the pancreas. Similar to the all the other cases in the literature review which required CT scan for diagnosis of the splenic abscesses.

Culture and isolation of $B$. pseudomallei from clinical samples are crucial tests for diagnosis. Abscesses in abdominal organs are well reported, especially in kidney, spleen and prostate. A study from Singapore reported that Burkholderia pseudomallei is the most common etiological agent for splenic abscesses. [11] Prolonged antibiotic therapy is required for treatment of visceral melioidosis. Typically, it is susceptible to ampicillin/sulbactam, chloramphenicol, tetracycline,

Bactrim [sulphamethoxazole- trimethoprim], third- generation cephalosporins and carbapenem. ${ }^{[12]}$ Therapies generally suggested for 10-14 days followed by oral antibiotics for a minimum of 3 months. In cases of treatment failure or worsening abscesses despite antibiotics, surgery is indicated.

Splenectomy has long been considered the standard treatment of splenic abscess. It can be done via open or laparoscopic method. In patients without prior abdominal surgery, stable hemodynamics status and in institution where surgical expertise is available, laparoscopic approach should be attempted. Hakan et al reported that laparoscopic splenectomy is superior with regards to hospital stay, start time to diet, wound infection and cosmesis. [13] Laparoscopic approach is superior as patients will have smaller scar, shorter recovery time and length of stay. In our region, 112 robotic hepatopancreato-biliary cases were performed over a 5 -year period. ${ }^{[14]}$ The high number of caseload demonstrated that our institution is capable of performing laparoscopic splenectomy. The analysis: of comparative trials of laparoscopic versus open splenectomy are also in favour of laparoscopic splenectomy. ${ }^{[15]}$

In our report, 2 patients underwent laparoscopic distal pancreatectomy and splenectomy while the other 2 had open conversion due to dense adhesions. All patients recovered well from the operation with no post-operative complications. Patients who underwent surgery benefited from shorter duration of antibiotics [6 weeks instead of 3 months] except in cases with synchronous infection. We had demonstrated that laparoscopic splenectomy with/ without distal pancreatectomy is a safe and effective method in treating pancreato-splenic abscess from melioidosis who failed the conservative management.

\section{Conclusion}

In conclusion, splenic and pancreatic melioidosis who failed medical treatment with antibiotics should be considered for surgery. Laparoscopic approach, while technically difficult, can be successful in selected patients in experienced hands. 


\section{DECLARATIONS}

\section{Conflicts of interest}

All authors declared that there are no conflicts of interest.

\section{Authors' contributions}

Made substantial contributions to conception and design of the study and performed data analysis and interpretation: HJ Tan, LS Lee, AKH Chiow, N Thiruchelvam, SS Tan

Performed data acquisition, as well as provided administrative, technical, and material support: HJ Tan, LS Lee

\section{Availability of data and materials}

Not applicable

\section{Financial support and sponsorship}

None.

\section{Consent for publication}

Informed consent was obtained from participating individual included in the report.

\section{Copyright}

(c) The Author[s] 2021.

\section{References}

[1]. Currie BJ. Melioidosis: evolving concepts in epidemiology, pathogenesis, and treatment. Semin Respir Crit Care Med 2015;36:111-25. doi: 10.1055/s-0034-1398389. Epub 2015 Feb 2.

[2]. Churuangsuk $\mathrm{C}$, Chusri S, Hortiwakul T, et al. Characteristics, clinical outcomes and factors influencing mortality of patients with melioidosis in southern Thailand: a 10-year retrospective study. Asian Pac J Trop Med 2016;9:256-60. doi: 10.1016/j.apjtm.2016.01.034. Epub 2016 Jan 11.

[3]. Bhengsri S, Baggett $\mathrm{HC}$, Jorakate $\mathrm{P}$, et al. Incidence of bacteremic melioidosis in eastern and northeastern Thailand. Am J Trop Med Hyg 2011;85:117-20. doi: 10.4269/ajtmh.2011.110070

[4]. Lee YL, Lee SJ, Tsai HC, et al. Pyogenic liver abscess caused by Burkholderia pseudomal-lei in Taiwan. J Formos Med Assoc 2006;105:68993. doi: 10.1016/s0929-6646[09]60171-6.

[5]. Cheng AC, Currie BJ. Melioidosis: epidemiology, pathophysiology, and management.Clin Microbiol Rev. 2005 Apr; 18[2]:383-416. doi: 10.1128/CMR.18.2.383-416.2005
[6]. Reactivation of latent melioidosis presenting with acute pyelonephritis and bacteremia. Shaaban H, Hallit R, Slim J, Sree A, Sensakovic JW. Avicenna J Med. 2014 Jan; 4[1]:20-1. doi: 10.4103/2231-0770.127418

[7]. Lumbiganon $P$, Viengnondha S. Clinical manifestations of melioidosis in children. Pediatr Infect Dis J 1995;14:136-40. doi: 10.1097/00006454-199502000-00010.

[8]. Singh M, Mahmood M. Melioidosis: the great mimicker. J Community Hosp Intern Med Perspect. 2017 Oct; 7[4]:245-247. doi: 10.1080/20009666.2017.1348875.

[9]. Huang, W., Wu, G., Chen, F. et al. Multisystemic melioidosis: a clinical, neurological, and radiological case study from Hainan Province, China. BMC Infect Dis 18, 649 [2018]. https://doi.org/10.1186/s12879-018-3569-8.

[10]. Joazlina ZY, Wastie ML, Ariffin N. Computed tomography of focal splenic lesions in pa-tients presenting with fever. Singapore Med J 2006;47:37-41. PMID: 16397719

[11]. Ng CY, Leong EC, Chng HC. Ten-year series of splenic abscesses in a general hospital in Singapore. Ann Acad. Med Singapore 2008; 37:749-752. PMID: 18989490

[12]. White NJ, Dance DA, Chaowagul W, Wattanagoon Y, Wuthiekanun V, Pitakwatchara $\mathrm{N}$. Halving of mortality of severe melioidosis by ceftazidime. Lancet 1989;23:697-701. doi: 10.1016/j.ijantimicag.2014.01.005

[13]. Bulus $H$, Mahmoud $H$, Altun $H$, Tas $A$, Karayalcin K. Outcomes of laparoscopic versus open splenectomy. J Korean Surg Soc. 2013 Jan;84[1]:38-42. doi: 10.4174/jkss.2013.84.1.38.

[14]. Lee, L., Wong, J., Chiow, A., Lee, S., Chan, C., Tan, S., Teo, J., Goh, B.. The develop-ment of robotic hepatopancreatobiliary surgery in Singapore: a multi-institutional experi-ence. Annals of Laparoscopic and Endoscopic Surgery, North America, 3, jul. 2018. doi: 10.21037/ales.2018.07.03

[15]. Targarona EM, Cerdán G, Gracia E, Rodríguez M, Trias M. Results of laparoscopic splenectomy for treatment of malignant conditions. HPB [Oxford]. 2001;3[4]:251-5. doi: 10.1080/136518201753335746.

[16]. Hai Chen, Zhi-qiang Hu, Yao Fang, Xiao-xue Lu, Li-da Li, Yuan-li Li et al. Splenic abscess caused by Burkholderia pseudomallei. Medicine [2018] 97:26. doi: 10.1097/MD.0000000000011208.

[17]. Deng-Wei Chou and Yie-Wen Lin. Splenic Infarction and Rupture Due to Melioidosis. Am J Med Sci. 2017 Dec;354[6]:633-634. doi: 10.1016/j.amjms.2016.12.009. Epub 2016 Dec 14 
[18]. Ninan F, Mishra AK, John AO, lyadurai R. Splenic granuloma: Melioidosis or Tuberculosis?. J Family Med Prim Care 2018;7:271-3. DOI: 10.4103/jfmpc.jfmpc_171_17

[19]. Liv Hesstvedt, Marianne Wilhelmsen, Anne Torunn Mengshoel, Anne Ma Dyrhol-Riise. Two Norwegian Patients With Melioidosis Presenting With Bacteraemia and Splenic and Prostatic Abscesses, Journal of Travel Medicine, Volume 18, Issue 6, 1 November 2011, Pages 418-421, https://doi.org/10.1111/j.1708-

8305.2011.00550.x

[20]. Miraclin AT, Mani SS, Suresh S, lyyadurai R. Septicemic melioidosis with ruptured splenic abscess in a patient with thalassemia intermedia. J Global Infect Dis 2017;9:32-3. DOI: 10.4103/0974-777X.194372

[21]. Jitendranath $A$, Bhargavi L, Ramani Bai $J T$, Radhika R. A case of melioidosis from splen-ic abscess. J Acad Clin Microbiol 2016;18:40-3. DOI: 10.4103/0972-1282.184765

[22]. Tak Kuan Chow, Lin Chuan Eu, Kin Fah Chin, Kien Chai Ong, Jayalakshmi Pailoor, Jamunarami Vadivelu et al. Case Report: Incidental Splenic Granuloma due to Burkholderia pseudomallei: A Case of Asymptomatic Latent Melioidosis?Am. J. Trop. Med. Hyg., 94[3], 2016, pp. 522-524. doi:10.4269/ajtmh.15-0774

[23]. Seymour Levine, Thomas J. Whelan. Melioidosis of the spleen. Am J Surg. 1968 Jun;115[6]:849-53.

Doi: https://doi.org/10.1016/0002-9610[68]90533-3

[24]. Maytapa, J., Thanapirom, K., Kullavanijaya, P., and Komolmit, P. [2018] Gastrointestinal: Splenic abscesses-related gastrosplenic fistula: Unusual complication of melioidosis. Jour-nal of Gastroenterology and Hepatology, 33: 1163. doi: 10.1111/jgh.14095.

[25]. Wu YC, Hsu JW, Chang TH, \& Kung WC. Melioidosis in an urban-dwelling Taiwanese man with splenic abscesses. Trop Doct. 2010 Oct;40[4]:240-1. doi: 10.1258/td.2010.090472. Epub 2010 Aug 13. 